\title{
Ao leitor sem medo
}

\author{
JOSÉEISENBERG
}

RESUMO: O texto resenha Ao leitor sem medo, de Renato Janine Ribeiro (Belo Horizonte, UFMG, 1999).

or que resenhar a segunda edição de um livro lançado quinze anos atrás? Como aponta o próprio autor no prefácio, desde que a primeira edição esgotou há mais de uma década, o livro vem circulando nos corredores das universidades brasileiras em fotocópias encadernadas, o que sem dúvida justifica sua reedição. Mas o que justifica uma resenha deste livro, se ele passou por poucas revisões de conteúdo na preparação desta edição? O objetivo da presente resenha de Ao Leitor sem Medo, de Renato Janine Ribeiro, é tentar fazer um balanço das mudanças no cenário das interpretações de Hobbes durante o período que separa esta edição da primeira, e avaliar se a interpretação de Renato Janine Ribeiro, sem dúvida uma das principais referências críticas de Hobbes em língua portuguesa, permanece atual. Em particular, o apêndice dois à segunda edição - um artigo metodológico escrito pelo autor pouco tempo após a publicação do livro permite-nos uma reflexão sobre o diálogo travado por Janine naquele artigo com o contextualismo pregado por Quentin Skinner, responsável pela mais importante obra de interpretação de Hobbes publicada no intervalo entre a primeira e a segunda edição do livro de Janine, e recentemente traduzida para o português (cf. Skinner, 1999).

Nas últimas três décadas, o estudo da história das idéias tem se
UNITERIMOS: Thomas Hobbes, filosofia política, história das idéias.

Professor do Departamento de Ciência Política da FAFICH - UFMG 
beneficiado do aparecimento de uma nova metodologia desenvolvida em torno da expressão "as linguagens da teoria política". Tendo como principal referência os escritos metodológicos de Quentin Skinner e J. G. A. Pocock, essa nova abordagem vem se tornando largamente aceita como um meio efetivo de se estudar idéias no contexto histórico e retórico em que foram produzidas. De acordo com Skinner e Pocock, textos teóricos são escritos por pessoas movidas por intenções e a produção de novas idéias deve portanto ser compreendida como um ato comunicativo através do qual o autor se dirige a uma audiência, em um determinado contexto que é, ao mesmo tempo, histórico e lingüístico. O resultado desta premissa é um contextualismo focado no caráter pragmático de teorias e conceitos, dando ênfase à conexão entre as linguagens da política de um determinado período histórico e as mudanças conceituais que são sistematizadas nas doutrinas teóricas emergentes naquele período (cf. Tully, 1988; Pocock, 1971).

Muitos críticos argumentam que o método de Skinner e Pocock apresenta sérias limitações para a compreensão do surgimento de idéias em seus contextos históricos. No volume de críticas metodológicas a Skinner organizado por James Tully, seu método é criticado por não especificar qual a relação existente entre os fatos políticos do contexto histórico estudado e os tratados teóricos que emergem naquele período. As críticas mais contundentes neste volume, porém, vêm de críticos que condenam Skinner por desviar o debate metodológico da discussão sobre os problemas concretos de se escrever uma "história das idéias em seu contexto" para as questões mais remotas relativas à teoria dos atos de fala. Skinner remete ao conceito de ato de fala elaborado por John Austin para argumentar que cada proferimento é um lugar potencial para a ocorrência de uma mudança conceitual. Se por um lado a tentativa de Skinner de fundamentar sua abordagem neo-historicista através de uma apropriação da filosofia da linguagem de Austin tem criado mais problemas do que soluções para o entendimento da sua posição metodológica especialmente em um contexto intelectual de historiadores das idéias pouco familiarizados com a filosofia da linguagem contemporânea - por outro lado, isso não significa que as questões levantadas pelo autor sejam de todo irrelevantes. Se nosso objetivo é escrever uma história de como conceitos políticos se transformam, é necessário fundamentar a abordagem em uma interpretação sistemática do uso da linguagem em contextos pragmáticos.

Em seu artigo de 1985 que aparece como apêndice a esta edição de Ao Leitor sem Medo, Janine junta-se aos críticos de Skinner ao condenar o que ele chama de "pressa contextualizadora" desta nova metodologia: "O estudo de uma época, de suas tensões fundamentais etc., é essencial para a compreensão de seus escritos; mas tende - se adotado como ponto de partida metodológico - a produzir o mero enquadramento dos textos. Estes são convertidos em efeitos". Ao comentar o método de Skinner em As Fundações do Pensamento Político Moderno, Janine descreve uma das virtudes centrais deste método como sendo sua capacidade de explicar o "seqüestro 
de sentido" que opera na migração de temas, conceitos e metáforas de um período para outro, de uma linguagem da teoria política para outra. Mas critica o mesmo autor por limitar-se a um contextualismo que, embora competente em elucidar o contexto da obra, não explica como um determinado texto retrata ou refrata uma realidade ou problema. Refrações, argumenta Janine, não são apenas desvios de significado, mas também pistas para a interlocução às vezes silenciosa que existe entre o autor e sua audiência. Seria portanto um certo desprezo por "a quem o autor de dirige", sua audiência, a maior limitação do método skinneriano. Janine ilustra seu argumento com um artigo de 1972 do próprio Skinner sobre Hobbes: o leitor do Leviatã não é somente "o aristocrata resignado a submeter-se a Cromwell", com argumenta Skinner, mas inclui até mesmo republicanos moderados. Vale lembrar que o próprio Skinner corrige este equívoco em seu recente livro sobre Hobbes, quando na conclusão aponta que o Leviatã, se comparado ao De Cive e aos The Elements, é um livro escrito para um novo tipo de público, mais amplo e menos instruído que aquela aristocracia resignada.

A crítica de Janine a Skinner parece-me pungente quando aponta que o texto deve vir antes do contexto. Diferente do que pensa o historiador inglês, o contexto não resulta da biografia do autor e sua coincidência com um conjunto de eventos históricos linearmente arranjados aos quais o autor supostamente remete os seus argumentos. A produção do contexto é um trabalho intelectual do leitor de Hobbes, e o primeiro e mais importante passo para descrever este contexto é um exercício hermenêutico debruçado sobre as páginas do texto. Charles Taylor, em seu artigo no volume organizado por James Tully, corrobora a crítica de Janine quando argumenta que o método de Skinner abandona seu aspecto hermenêutico quando antecipa os significados do texto na reconstrução do contexto e nas linguagens da política nele faladas.

Mas o que podemos dizer do método empregado pelo próprio Janine em Ao Leitor sem Medo? Mais hermenêutico do que Skinner, ainda que menos historiador, Janine mostra-se capaz de apreender e explicitar alguns aspectos da obra de Hobbes que, depois de tantos anos, continuam ausentes das interpretações de Hobbes produzidas na Europa e no Estados Unidos. Destaca-se entre estes aspectos, a sua leitura do homem feminino hobbesiano e a comparação com Don Juan. A hermenêutica de Janine, sofisticada e corretamente situada no diálogo que trava com a literatura secundária sobre Hobbes produzida no pós-guerra, nos deixa no entanto sem pistas de como ela opera, explicitando seu método somente através de metáforas como "refração", e negligenciando uma das características fundamentais do exercício hermenêutico, qual seja, a reinvenção das tradições e a tradução do objeto realizada pelo sujeito da interpretação. Ausente deste momento reflexivo imperativo a toda hermenêutica, o método de Janine acaba por não completar o círculo e explicitar a relação entre o seu exercício de explicação e a autocompreensão de seu objeto, o pensamento político de Hobbes.

Estes silêncios no plano metodológico não subtraem atualidade da 
interpretação de Janine, melhor compreendida em sua interlocução com Leo Strauss. Ainda que Macpherson seja um autor mais proeminente nos diálogos de Janine com a literatura secundária - afinal o livro foi escrito em um período no qual A Teoria do Individualismo Possessivo ainda exercia uma enorme influência sobre o milieu acadêmico - é o seu diálogo com Strauss que produz o mais original e atual de seus argumentos. Coube a Strauss apontar a centralidade do medo na construção do modelo de consentimento hobbesiano em seu clássico texto The Political Philosophy of Hobbes: its basis and its genesis (1936), e até hoje, em salas de aula de graduação e pós-graduação, é este o argumento que é apresentado àqueles que estão sendo introduzidos à obra do filósofo inglês: a teoria política de Hobbes teria como alicerce o medo gerado pela brutalidade do estado de natureza, e é deste sentimento que floresce a vocação política do homem, vocação esta marcada principalmente pelo imperativo da obediência.

Janine não refuta este argumento, mas complementa-o com outro central à compreensão do pensamento hobbesiano. A vocação política do homem em Hobbes não nasce somente do medo, e não se reduz portanto à revelação do imperativo da obediência. O sentimento irmão do medo no pensamento hobbesiano - a esperança - também participa da produção daquela vocação, pois se o medo impele o homem a pensar no seu futuro e nas formas de evitar o objeto de seu medo, é a esperança que o projeta para o futuro e, mais importante ainda, é ela que leva o homem a crer que o contrato de submissão a que está preste a realizar pode efetivamente eliminar o objeto do medo. Este momento (republicano, talvez?) do pensamento hobbesiano escapa a intérpretes do filósofo inglês desde que Strauss escreveu seu livro, mas não escapou a Janine.

Não há como negar que, nos dias de hoje, a interlocução insistente de Janine com C. B. Macpherson retira do livro um pouco de sua atualidade. Resultado de uma reflexão viciada pelas adjetivações advindas do marxismo anglo-americano do pós-guerra, a interpretação que Macpherson faz de Hobbes é fruto de algumas simplificações primárias orientadas pelo seu desejo de estabelecer as continuidades entre dois autores (Hobbes e Locke) cujos pensamentos políticos pouco têm em comum para além da adoção do modelo contratual que outorga ao consentimento o papel de legitimador da autoridade política. Em alguns momentos do livro de Janine, o leitor mais judicioso da filosofia política inglesa se sente um pouco traído pela dedicação quase exclusiva que o autor dá àquele comentarista. Mas não podemos condenar Janine por dialogar com uma das obras mais influentes do período no qual a tese de doutorado que deu origem ao livro foi escrita. Se o livro de Macpherson é expressão daquele contexto marxista do pós-guerra, o livro de Janine expressa um contexto de reação e revisão na historiografia da filosofia política moderna. Desta reação e revisão fazem parte outros leitores importantes de Hobbes que também se tornaram vítimas da interlocução com Macpherson, como Richard Tuck. 
É a este último intérprete que devemos uma das mais lúcidas tentativas de sistematizar a diferentes recepções de Hobbes nesta historiografia (cf. Tuck, 1989). Tuck identifica quatro tipos de interpretação e recepção de Hobbes após a sua morte. Toda a tradição até o século XIX interpretava Hobbes como um autor jusnaturalista, sendo um dos autores mais citados nos tratados de direito natural até o final do século XVIII. Pufendorf é o primeiro a apontar para a importância do trabalho de Hobbes, ainda durante a sua vida, em Lei da Natureza e das Nações (1672). No século XIX, Hobbes perde um pouco da sua popularidade entre autores jusnaturalistas. Em Hegel, por exemplo, Hobbes é tratado com um autor menor. Para autores saindo da escola utilitarista, Hobbes era um autor simpático por causa de sua construção política a partir da psicologia do indivíduo e o papel dos interesses na formação da sociedade civil, mas nunca o ponto de partida, já que sua teoria do direito natural era incompatível com a teoria jurídica dos utilitaristas. É durante este século também que Robertson publica a primeira biografia acadêmica de Hobbes (1876), mas coube a Toennies recuperar a importância deste autor em sua obra sobre o seu desenvolvimento intelectual.

Se até a década de 30 deste século prevalece esta leitura jusnaturalista de Hobbes, de 1930 a 1965 a interpretação de Hobbes é pontuada pelas obras de Strauss $(1934,1953)$ e Macpherson $(1945,1962)$, ambos apresentando-o, mesmo que de perspectivas radicalmente diferentes, como precursor da modernidade, ou um dos seus fundadores. Após a segunda guerra mundial, um outro tipo de interpretação de Hobbes retrata-o como precursor de uma ciência social neutra, partindo de atributos psicológicos universais dos homens. Destacam-se entre aqueles que assim o interpretaram Watkins, em Hobbes' system of ideas (1965), que define a temática hobbesiana como metodológica, centrada no método resolutivo-compositivo, e Gauthier, em Logic of Leviathan (1969), segundo o qual Hobbes já havia entendido o dilema do prisioneiro. Ao mesmo tempo, em outras obras como The Political Philosophy of Hobbes: his theory of obligation (1957) de Warrender, e The Moral Life in the Writings of Thomas Hobbes (1960) de Oakeshott, surge uma interpretação de Hobbes como um moralista, onde o problema da obrigação moral do soberano é arbitrariamente estipulada sem argumentação alguma. A esta tipologia de Tuck devemos talvez adicionar o Hobbes mestre da retórica que aparece no livro recente de Skinner. Naquele livro, Skinner nos apresenta ainda um outro Hobbes, pai da filosofia política em língua inglesa, preocupado com a construção na língua vernácula de uma nova matriz conceitual para a interpretação da política.

Mas aonde se encaixa, então, a interpretação de Janine nesta tipologia? Prima facie, ela não se encaixa perfeitamente em nenhuma das categorias descritas acima. O Hobbes de Janine não pode ser classificado nem de jusnaturalista, nem de cientista social, nem de precursor da modernidade, e menos ainda de moralista ou mestre da retórica, ainda que Janine aponte para traços de todas estas categorias no filósofo inglês. O Hobbes de Janine, como 
indica o subtítulo de seu livro, escreve contra o seu tempo, e seu tempo é marcado por diálogos intelectuais onde direito, ciência, modernidade, moral e retórica constituem áreas de reflexão teórica que não estão e nem podem ser dissociadas uma das outras. Não faz sentido atribuir a preponderância de um aspecto ou outro à obra de Hobbes. Podemos dizer que Janine, diferente de seus antecessores, não comete nem a falácia teleológica de atribuir a um autor em seu tempo a premonição ou conhecimento germinal de idéias de tempos futuros, nem a falácia reducionista de remeter o pensamento daquele autor a um único problema teórico ou metodológico. Podemos dizer portanto, que se a obra de Hobbes discursa ao leitor sem medo, o livro de Janine traz ao leitor a esperança de uma compreensão mais profunda das sutilezas de um dos maiores filósofos políticos da era moderna. Felizmente nós, seus leitores de língua portuguesa, que durante anos tivemos acesso a seu interessante estudo somente através de reproduções clandestinas, agora podemos comprar o livro.

Recebido para publicação em março/2000

UNITERIMS:

Thomas Hobbes, political philosophy, the history of ideas.
ABSTRACT: This text is a review of Ao leitor sem medo by Renato Janine Ribeiro (Belo Horizonte, UFMG, 1999).

\section{REFERÊNCIASBIBLIOGRÁFICAS}

Pocock, J. G. A. (1971) Politics, language and time. New York, Atheneum.

SKINNER, Quentin. (1999) Razão e retórica na filosofia de Hobbes. São Paulo, Unesp.

Tuck, Richard. (1989) Hobbes. Oxford, Oxford University Press.

Tully, James (org.). (1988) Meaning and context: Quentin Skinner and his critics. Princeton, Princeton University Press. 